UCRL-2794

Unclassified Chemistry

UNIVERSITY OF CALIFORNIA

Radiation Laboratory

Berkeley, California

Contract No, w-7405-eng-48

EFFECTS OF IONIZING RADIATION ON CHOLINE CHLORIDE AND ITS ANALOGS

Richard M. Lemmon, Margaret A. Parsons, and Doris M. Chin

December 1954

Printed for the U.S. Atomic Energy Commission 


\title{
EFFECTS OF IONIZING RADIATION ON CHOLINE CHLORIDE AND ITS ANALOGS
}

Richard M. Lemmon, Margaret A. Parsons, and Doris M. Chin

Radiation Laboratory, Department of Physics

University of California, Berkeley, Catifornia

December 1954

\begin{abstract}
Choline chloride and six analogo have been exposed in the dry, eryatalline state to high-energy electron and gamma radiation. This investigation has confirmed the abnormal radiation sensitivity of choline chloride. Its $\mathrm{G}$ values (molecules decomposed/100 ev) were found to be: $e^{*}$-radiation, 20; $\gamma$-radiation, 175. These high values indicate a chain mechanism for the solid-state reaction. The $G$ values for the choline analogs were found to range from I to 18 for the electron irradiations and from it to 32 for the gamna irradiations. Betaine hydrochloride approaches choline chloride in instability toward high-energy electrons but is far more stable in the presence of $\gamma$-rays.
\end{abstract}




\section{EFFECTS OF IONIZING RADIATION ON CHOLINE CHLORIDE AND ITS ANALOCS!}

Richard M. Lemmen, Margaret A. Parsons, and Doris M. Chin

Radiation Laboratory, Department of Physice

University of Califoraia, Berkeley, Californis

\section{December 1954}

The abnormal senaitivity of anhydrous, erystalline choline -methyl-c| $\left.\right|^{4}$ chloride toward its own radiation 2,3 and the simplicity of its decomposition product (only trimethylamine and acetaldehyde were observed) bas led to the present study of the effects of high-energy radiation on this compound and on six of ita analogs. The objects of this work were to confirm the abnormal sensitivity of the choline chloride molecule and to determine the effects of changes in the molecule on this radiation sensitivisy. Electron $(2-4 \mathrm{Mv})$ and gamma (1.3 Mev) irradiations have been carried out on the dry, eryatalline salts maintained under vacuum during the bombardments. The compounds irradiated and the average sensitivities measured are listed in Table $\mathrm{I}$.

A further objective of this work was to learn more about the eflects of

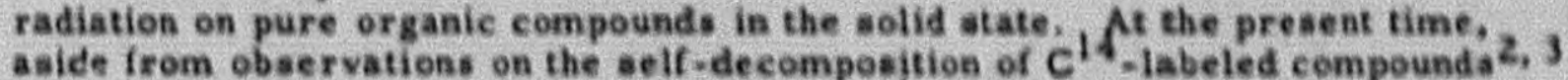
and the radiation initiation of polymesisation, 4 the only reported measurements of the radiation decomposition of solid-state grganic compounde are those on giycine 5 and some of the carboxylic acids. 6,7

I The work described in this paper was sponsored by the $\mathrm{U}$, $\mathbf{S}$, Atomie Energy Commission and was presented before the Division of Organie Chemistry at the September 1954 Meeting of the American Chemical Society.

2 B. M. Tolbert et al, J. Am, Chem, Soe, 75, 1867 (1953).

3 R. M. Lemmon, Nucleonies 11, No, 10, 44 (1953).

4 A. Charlesby, Nucleonics 12, No, 6, 18 (1954).

5 W. M. Dale, J. V, Davies, and C. Gliberi, Biochem, J. 45, 93 (1949),

6 W. L. Whitehead, C. Goodman, and I. A. Breger, J, chim. phys, 48, 184 (1951).

7 V. L. Burton, J. Am, Chem, Soc, 71, 4117 (1949). 
Radiation Decomposition of Chotine Aastoge = Iable 1

\begin{tabular}{|c|c|c|c|}
\hline \multirow[b]{2}{*}{ * Compound } & \multicolumn{3}{|c|}{$0 * \frac{\text { molecules decomposed }^{4}}{100 \mathrm{er}}$} \\
\hline & $c^{14} \cdot 8$ & 2-4-Mvelestrens & 1.3. Mer Y \\
\hline$\left.\left(\mathrm{CH}_{3}\right)_{3} \mathrm{NCH}_{2} \mathrm{CH}_{2} \mathrm{OH}\right]^{\prime} \mathrm{Cl}$ " & 1250 & 20 & 175 \\
\hline$\left.\left\{\mathrm{CH}_{3}\right)_{3} \mathrm{NCH}_{2} \mathrm{CH}_{2} \mathrm{OH}\right\}^{+}{ }^{*}$ & * & 2 & 5 \\
\hline$\left.\left(\mathrm{CH}_{3}\right)_{3} \mathrm{NCH}_{2} \mathrm{CH}_{2} \mathrm{OCOCH}\right]^{+} \mathrm{Cl}^{*}$ & 5 & 2 & 4 \\
\hline$\left.\left\{\mathrm{CH}_{3}\right)_{3} \mathrm{NCH}_{2} \mathrm{CH}_{2} \mathrm{CH}_{2} \mathrm{Or}\right\}^{+} \mathrm{Cl}^{*}$ & $*$ & 2 & 4 \\
\hline$\left.\left[\mathrm{CH}_{3}\right)_{3} \mathrm{NCH}_{2} \mathrm{CH}_{3}\right]^{+} \mathrm{Cl}^{*}$ & - & 2 & 2 \\
\hline$\left.\left[\mathrm{CH}_{3}\right)_{3} \mathrm{NCH}_{2} \mathrm{CH}_{2} \mathrm{Cl}\right]^{+} \mathrm{Cl}^{*}$ & * & 3 & 12 \\
\hline$\left.\left[\mathrm{CH}_{3}\right)_{3} \mathrm{NCH}_{2} \mathrm{COOH}\right]^{4} \mathrm{Cl}^{*}$ & * & 14 & 18 \\
\hline
\end{tabular}

a These $\mathrm{Q}$ values should not be cossidered os more than rough indications of relative stabitities; they may be in error by as much as a factor of two.

\section{Experimental}

\section{Preparation of Choline Analoge}

All the compounds used in this work were prepared with very small amounts of earbon-14 in the methyl groups. Chotine-methyl=C 4 iodide (op, act, $0.1 \mathrm{\mu e} / \mathrm{mg}$ ). was prepared by reacting $\mathrm{C}^{4} \mathrm{H}_{3} \mathrm{I}$ with dimethylaminoethanol in methanol solution and recryatalliaing the product from absolute ethanol-ether. (All the preparationa, with the exception of trimethyl-3-hydroxypropyl ammonium chloride, as noted below, were recrystallised from this solvent.) The chloride was prepared from the lodide through conversion to the quaternary base with $A_{82} \mathrm{O}$, followed by titration with KCI. Acetylcholine chloride was prepared by refluxing the labeled choline chloride with acetic anhydride for 2 to 3 hours. The trimethyl.2. chloroethyl ammonium chloride was prepared by reacting the choline chloride- $\mathrm{C}^{14}$ with thionyl chloride at room temperature.

Trimethyl-c $\left.\right|^{4}-3$-hydroxypropyl ammonium chloride (op. act, $1.0 \mu \mathrm{e} / \mathrm{mg}$ ) was prepared from labeled trimethylamine and 3-chloropropanot the product was recryatallized from absolute ethanol-dioxane. Trimethyl-C|4.ethyl ammonium chloride (sp. act. $0,1 \mu \mathrm{c} / \mathrm{mg}$ ) was prepared by reacting labeled trimethylamine with ethyl lodide, followed by converaion of the quaternary lodide to the chloride.

Betaine-methyl-c $\left.\right|^{4}$ hydrochloride was prepared by reacting labeled trimethylamine with excess chloroacetic acid in methanol solution at room temperature. The product was separated from chloroacetic acid on a Dowex-50 
catien exchange column Acceptable carbon, bydrogen, nitrogen, and halegen analyoes (atl within 0.35 of the calculated values) were sbtained on all com: poundo used in these radiation studies.

\section{Irradiation Procedure.}

For the velf-decomposition experiments, two samples of analytically pure crystalline choline chloride (sp. act. $0.6 \mathrm{\mu e} / \mathrm{mg}$ and $10.7 \mathrm{\mu c} / \mathrm{mg}$ ) were prepared separately. These samples were stored at room temperature in the dark in sealed ampoules under high vacuum. The firat sample was stored for 46 months, the accond for 46 daya. Another portion of the second sample was stored at $=196^{\circ} \mathrm{C}\left(1 \mathrm{iq}, \mathrm{N}_{2}\right.$ ), otherwise all conditions were the same.

For the high-energy electron irradiations, 50 to $200 \mathrm{mg}$ of the analytically pure sample was placed in a small watch-shaped container. Because of the hygroscopic nature of these compounds, tranafers from one container to another were carried out in a dry box in an atmosphere of dry nitroger. The Aat sides of the container were $\mathrm{f} \mathrm{cm}$ in diameter, the glass was about $1 \mathrm{~mm}$ thick, and the diatance between the glass walls was about $2 \mathrm{~mm}$. After the sample was placed in the container it was redried at 1000 for severat hours under a high vacuum and, finally, the tube was sealed off under vacuum. The irradiations were carried out using the beam of a 3to-4-Mv linear electron accelerator. The number of electrons passing through the sample. was measured by a brass collector (atso $1 \mathrm{~cm}$ is diameter) placed immediately behind the sample holder; this collector was connected to an ammeter and grounded through a $10^{6}$.ohm resistor. Bccause of such factors as the stoppage of some electrons by the sample itself and by the glass walls, scattering of electrons by sample and container, secondary electron emisaion, and air ionization, the absolute amount of energy received by the sample is probably not knewn within a factor of two. However, the comparative values for the various choline analogs are probably eorrect to within $\neq 25 \%$. Calculations of the energies received by the samples were made as follows?

No. of electrons passing through sample $=\mathrm{N} * \frac{(\text { amps) }}{\text { coulombs/electron }}$

Energy loss in Mev/electron $=\Delta \mathrm{E}=\frac{\Delta R}{0.54} \quad$ (Feather', rule for energies $>0,8 \mathrm{Mev}$ )

$\mathrm{Mev} / \mathrm{g} / \mathrm{rep}=(93 \mathrm{ergs} / \mathrm{g} / \mathrm{rep})\left(\frac{6 \times 10^{23} \mathrm{ev}}{96,500 \times 10^{7} \text { ergo }}\right)\left(10^{\circ 6} \mathrm{Mev} / \mathrm{ev}\right)$

$=5.2 \times 10^{7}$

$\therefore$ rep received by sample $=\frac{(N)(\Delta E)}{(8)\left(5.2 \times 10^{7}\right)}$ 
Duriag the ircadiationa the samples, which received energy at a rate of approximately 107 rep/minate, were kept between room temperature and a maximum of $50^{\circ}$ by means of as air blast.

The $\gamma$-irradiations were carried out in a 100 -curie $\mathrm{Co}^{60} \mathrm{y}$-ray source, Through the uge of a ceric lon dosimeler this source was found to deliver 1.7 . $0.3 \times 10^{5}$ rephour. As with the electron irradiations, all y-irradiations were carried out on analytically pure crystalline samples contained in sealed tubes under high vacuum

The $\mathrm{O}$ values, 9 or molecules decomposed per $100 \mathrm{ev}$ of absorbed energy, were calculated a followa for both types of irradiations:

1 rep $=5.2 \times 10^{13} \mathrm{ev} / \mathrm{gram}$.

$\frac{\text { Molecules decomposed }}{100 \frac{\mathrm{V}}{2 \mathrm{~V}}} * \frac{\left(\frac{6.02 \times 10^{23}}{\mathrm{~mol} \cdot \mathrm{Wt}}\right)\left(\frac{8 \text { decomposed }}{100}\right)}{(\text { rep })}$

$\frac{\left(\text { S decomposed) } 11.16 \times 10^{10}\right)}{(\text { rep }) \text { (mol. Wh. })}$

\section{Analyticat Procedures}

Two procedurea have been used to determine the extent of decomposition of the irradiated materiala: reineckate analysia and paper chromatography.

Reineckate analyses have been used to determine the extent of decom. position of all the chotine asaloga with the exception of the trimethyl-3. hydroxypropyl ammonium chtoride, Is ppplying this method we have in general followed the procedure of Glick if in which the guaternary ammonium caston ia precipitated out of aqueous solution by the anion of ammonium reineckate, $\mathrm{NH}_{4}{ }^{*}\left[\mathrm{Cr}(\mathrm{SCN})_{4}\left(\mathrm{NH}_{3}\right)\right]$ ". Before the addition of this reagent, the irradiated compounds were bolled for 15 minutes in $0.1 \mathrm{~N}$ KOIl aolation in order to eliminate any trimethylamine formed by the irradiation, and then neatralliaed. The precipitated quaternary ammonium reineckate was freed of ammonium reineckate by washing with $n$-propanol, then dissolved in acetone, and ito concentration was determinea by means of its optical denaity at $526 \mathrm{mp}$. The molar extinction coefficient for choline reineckate was determined by Glick to be 111 , our value is 109. The molar extinction coefficien's for the reineckates of eholine bodide, trimethyl-z-chloroethyl ammonium chloride, and trimethylethyl ammonium chloride were found to be 111,111 , and 109 , respectively; these values are all very nearly the same because the optical density at $526 \mathrm{m \mu}$ is due only to the reineckate molety. Acetylcholine was determined as choline by a prior hydrolysis accomplished by boiling for 19 minutes in 0.1 NKOH solution. For all the analogs for which it was used, the error of the reineckate procedure in determining the amount remaining after an ir radiation is about $t 5 \%$.

8. T. J. Hardwick, Can, J. Chem, 30, 17 (1952),

9 M. Burton, J. Phys, and Colloid Chem, 51, 611 (1947).

10 D. Gilek, J, Biol. Chem. 156, 643 (1944). 
The reineckate procedure was found to be unsuited for the analyses of trimethyl-3-hydroxypropyl ammonium chloride, as no procedure could be found that would separate the reineckate of the quaternary ammonium salt from the ammonium reineckate reagent. Propanol washing was found to dissolve large fractions of the desired reineckate along with the unused reagent.

In the analygis of betaine hydrochloride the titration procedure of Walker

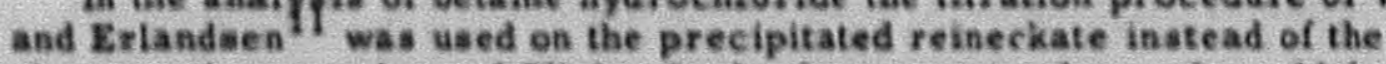
photometric procedure of Glick, In the former procedure, the acid function of the reineckate-precipitated betaine hydrochloride is determined titrimetrically. The presence of trimethylamine was found not to interfere with the Walker and Erlandsen procedure; however, deviations in results obtained under standard conditions indicate that the error involved in this procedure may be as high as $\pm 10 \%$.

Paper chromatography was alao used to measure the extent of decom position of the methyl-labeled choline analogs. This procedure was possible because the only labeled decomposition product found on either two-dimensional (phenol-water and butanol-propionic acid-water) or one-dimensional (butanol-HCl-water) chromatograms was trimethylamine. This product is formed as the hydrochloride (or hydrolodide) during the bombardments; volatile substances formed were never more than one percent (usually less than $0.5 \%$ ) of the total weight of the irradiated compound. This lack of volatility presumably is due to radiation polymerization of the product derived from the 2- or 3-carbon chain of the molecule. The trimethylamine was separated from unchanged choline analog by one-dimensional paper chromatography on Whatman No, I paper using the n-butanol-conc. HCl-water solvent (4:1:i by vol). In the case of the trimethyl-êthyl ammonium chloride, no separation from trimethylamine was achieved with the butanol solvent. A successful separation was effected, however, using a $95 \%$ ethanol-conc. $\mathrm{HCl}$ solvent (10:1 by vol). The position of the radioactive spots was established by radioausography and the amount of trimethylamine hydrochloride determined by counting directly on the pafer. The estimated error in this procedure is $110 \%$.

\section{Results}

The data obtained from the irradiation experiments are summarized in Table II. The $\mathrm{G}$ values given in these tables are subject to large errors and therefore can be taken as only rough approximations. The absolute values of total energy absorption for the high-energy electron irradiations are not known to better than a factor of two; for the self-irradiation of labeled choline chloride and the $y$-irradiation experimests the energies received are probably correct to $* 20 \%$. In addition, the $G$ values are subject to the errors introduced by the analytical techniques. These are particularly large when the decompositions are less than $5 \%$.

II H. G. Walker and R. Erlandsen, Anal. Chem. 23, 1309 (1951). 
Table II

Radiation Decomposition of Choline Analogs

\begin{tabular}{|c|c|c|c|c|c|}
\hline Compour. & $\begin{array}{l}\text { Type of } \\
\text { Radiation }\end{array}$ & $\begin{array}{r}\text { Rep } \\
\times 10^{-6}\end{array}$ & $\begin{array}{c}\% \\
\text { Decomp. }\end{array}$ & $\begin{array}{c}\text { G } \\
\text { (molecules } \\
\text { decomp.per } \\
100 \text { ev) }\end{array}$ & Method of Analysis \\
\hline $\begin{array}{c}\text { Chotine chloride } \\
\text { " }\end{array}$ & $\begin{array}{c}\mathrm{C}^{14} \text {-beta } \\
n\end{array}$ & $\begin{array}{r}10.7 \\
2.5 \\
1.5\end{array}$ & $\begin{array}{l}63 \\
54 \\
27\end{array}$ & $\begin{array}{l}490^{a} \\
1780^{\circ} \\
1490^{b}\end{array}$ & Paper chromatography \\
\hline $\begin{array}{l}" 1 \\
" 1 \\
" 1 \\
"\end{array}$ & $\begin{array}{c}2-4-\text { Mv electrons } \\
" \\
" 1 \\
" ~\end{array}$ & $\begin{array}{r}160 \\
57 \mathrm{c} \\
57 \\
127 \\
66 \\
\end{array}$ & $\begin{array}{l}51 \\
10 \\
10 \\
21 \\
16\end{array}$ & $\begin{array}{l}26 \\
23 \\
15 \\
14 \\
20\end{array}$ & $\begin{array}{l}\text { " } \\
\text { Reineckate } \\
\text { Paper chromatography } \\
\text { Reineckate } \\
\text { " }\end{array}$ \\
\hline $\begin{array}{c}" ~ \\
" ~ \\
" ~ \\
\text { Acetylcholine chloride }\end{array}$ & $\begin{array}{l}\mathrm{Co}^{60}{ }^{\circ} \text { y }(1.3 \mathrm{Mev}) \\
" " \\
" 1 \\
\mathrm{C}^{14} \text { _beta }\end{array}$ & $\begin{array}{l}37 \\
28 \\
28 \\
12 \\
127 \\
10,9\end{array}$ & $\begin{array}{r}72 \\
69 \\
64 \\
25 \\
22 \\
<1\end{array}$ & $\begin{array}{l}160 \\
200 \\
190 \\
173 \\
152 \\
<6\end{array}$ & $\begin{array}{l}\text { " } \\
\text { Paper chromatography } \\
\text { Reineckate } \\
\text { Paper chromatography } \\
\text { " }\end{array}$ \\
\hline $\begin{array}{l}" 1 \\
" 1 \\
" 1 \\
" 1 \\
"\end{array}$ & $\begin{array}{c}\text { 2-4-Mvelectrons } \\
" ~ \\
" 1 \\
" ~ \\
"\end{array}$ & $\begin{array}{l}220 \\
500 \\
57 \\
240 \\
240 \\
140 \\
140\end{array}$ & $\begin{array}{r}-8 \\
1 \\
16 \\
11 \\
3\end{array}$ & $\begin{array}{r}2.3 \\
-0.1 \\
1.1 \\
4.1 \\
3.9 \\
0.9 \\
1.4\end{array}$ & $\begin{array}{l}\text { Reineckate } \\
\text { Paper chromatography } \\
\text { Reineckate } \\
\text { Paper chromatography } \\
\text { Reineckate } \\
\text { Paper chromatography }\end{array}$ \\
\hline
\end{tabular}

a This result was reported in an earliex paper. See Reference 3.

b Another portion of this sample was otored at $-196^{\circ} \mathrm{C}$. It showed no measurable decomposition and, at

this temperature, probably has a G value of 3 to 4 .

c The brackets indicate that the amount of decomposition resulting from a given bombardment wa.

determined independently by the two methods of analysis. 


\begin{tabular}{|c|c|c|c|c|c|c|}
\hline - 4 & & & & & 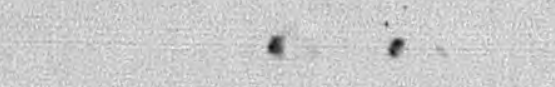 & \\
\hline Compound & $\begin{array}{l}\text { Type of } \\
\text { Radiation }\end{array}$ & $\begin{array}{r}\text { Rep } \\
\times 10^{-6}\end{array}$ & Decomp. & \begin{tabular}{|c|}
$\mathrm{G}$ \\
(molecules \\
decomp.per \\
$100 \mathrm{ev}$ )
\end{tabular} & Method of Analysis & \\
\hline $\begin{array}{c}\text { Acetylcholine chloride } \\
" \\
" 1 \\
"\end{array}$ & $\begin{array}{c}\mathrm{Co}^{60}-\underline{\gamma}(1.3 \mathrm{Mev}) \\
" 1 \\
" 1 \\
"\end{array}$ & $\begin{array}{l}101 \\
10 \\
56 \\
90 \\
90\end{array}$ & $\left.\begin{array}{r}-0 \\
-0 \\
4 \\
6 \\
4\end{array}\right\}$ & $\left.\begin{array}{l}\text { v. low } \\
\text { " } \\
4 \\
3\end{array}\right\}$ & $\begin{array}{l}\text { Reineckate } \\
\text { Paper chromatography } \\
\text { Reineckate } \\
\text { Paper chromatography }\end{array}$ & \\
\hline $\begin{array}{c}\text { Choline iodide } \\
\text { " } \\
" \\
" 1 \\
"\end{array}$ & 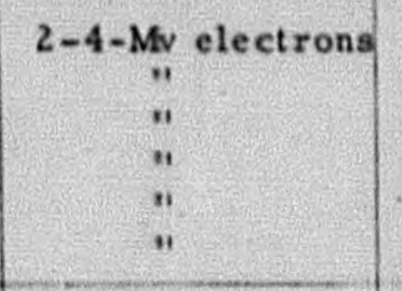 & $\begin{array}{l}70 \\
240 \\
240 \\
160 \\
160 \\
230\end{array}$ & $\left.\begin{array}{l}6 \\
2 \\
5 \\
7 \\
2 \\
3\end{array}\right\}$ & $\begin{array}{l}4.7 \\
0.4 \\
1.0 \\
2.4 \\
0.7 \\
0.8\end{array}$ & $\begin{array}{l}\text { Reineckate } \\
\text { " } \\
\text { Paper chromatography } \\
\text { Reinieckate } \\
\text { Paper chromatography } \\
\text { Reineckate }\end{array}$ & \\
\hline $\begin{array}{l}\text { " } \\
" 1 \\
" 1 \\
\text { " } \\
\end{array}$ & $\begin{array}{c}\mathrm{Co}^{60} \cdot \gamma^{(1.3 \mathrm{Mev})} \\
" 1 \\
" 1 \\
" 1\end{array}$ & $\left.\begin{array}{l}15 \\
28 \\
16 \\
16 \\
28 \\
28\end{array}\right\}$ & $\left.\begin{array}{r}1 \\
2 \\
5 \\
0 \\
3 \\
1\end{array}\right\}$ & $\left\{\begin{array}{r}3.4 \\
3.3 \\
17 \\
\text { low } \\
5.4 \\
1.8\end{array}\right\}$ & \begin{tabular}{l}
\multicolumn{1}{c}{$"$ " } \\
Paper chromatography \\
Reineckate \\
Paper chromatography \\
\end{tabular} & $\dot{b}$ \\
\hline$\left[\left(\mathrm{CH}_{3}\right)_{3,} \mathrm{NCH}_{2} \mathrm{CH}_{2} \mathrm{CH}_{2} \mathrm{OH}^{+}\right]^{+}$ & 2-4-Mv electrons & $\begin{array}{r}81 \\
390\end{array}$ & $\begin{array}{r}3 \\
11\end{array}$ & $\begin{array}{l}2.8 \\
1.9\end{array}$ & ," & \\
\hline 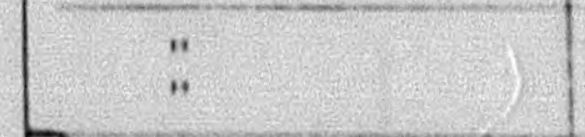 & $\mathrm{Co}^{60}-Y(1.3 \mathrm{Mev})$ & $\begin{array}{l}13 \\
27\end{array}$ & $\begin{array}{l}1 \\
1\end{array}$ & $\begin{array}{l}6 \\
3\end{array}$ & " & \\
\hline$\left[\begin{array}{c}\left.\left.\left(\mathrm{CH}_{3}\right)_{3,1} \mathrm{NCH}_{2} \mathrm{CH}_{2} \mathrm{Cl}\right]\right]^{+} \mathrm{Cl}^{-} \\
" \\
" \\
"\end{array}\right.$ & $\begin{array}{c}2-4-\mathrm{Mv} \text { electrons } \\
. \\
n \\
n \\
n \\
\end{array}$ & $\begin{array}{l}99 \\
101 \\
150 \\
150 \\
280 \\
280\end{array}$ & ${ }_{28}^{5} 4^{y^{\mathrm{d}}}$ & $\int_{7}^{4} \int^{d}$ & $\begin{array}{l}\text { Reineckate } \\
\text { " } \\
\text { " } \\
\text { Paper chromatography } \\
\text { Reineckate } \\
\text { Paper chromatography }\end{array}$ & 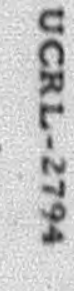 \\
\hline
\end{tabular}




\begin{tabular}{|c|c|c|c|c|c|}
\hline Compound & $\begin{array}{r}\text { Type of } \\
\text { Radiation }\end{array}$ & $\begin{array}{l}\text { Rep } \\
\times 10^{-6}\end{array}$ & $\begin{array}{c}\% \\
\text { Decomp. }\end{array}$ & $\begin{array}{l}\text { G } \\
\text { molecules } \\
\text { decomp.per } \\
\text { 100.ey }\end{array}$ & Method of Analysis \\
\hline$\left[\begin{array}{c}\left.\left(\mathrm{CH}_{3}\right)_{31} \mathrm{NCH}_{2} \mathrm{CH}_{2} \mathrm{Cl}\right]+\mathrm{Cl}^{-} \\
" " \\
" \prime\end{array}\right.$ & $\begin{array}{c}\mathrm{Co}^{60}-\gamma(1.3 \mathrm{Mev}) \\
" 1 \\
" \\
"\end{array}$ & $\left.\begin{array}{l}16 \\
13 \\
12 \\
12 \\
33\end{array}\right\}$ & $\begin{array}{c}7 \\
3 \\
\sim 0 \\
2 \\
\sim 0\end{array}$ & $\begin{array}{c}32 \\
17 \\
v . \text { low } \\
12 \\
v . \text { low }\end{array}$ & $\begin{array}{l}\text { Reineckate } \\
\text { ". } \\
\text { "" } \\
\text { Paper chromatography } \\
\text { Reineckate }\end{array}$ \\
\hline$\left[\left(\mathrm{CH}_{3}\right)_{3} \mathrm{NCH}_{2} \mathrm{COOH}\right]^{+} \mathrm{Cl}^{-}$ & 2-4-Mvelectrons & $\begin{array}{l}60 \\
89\end{array}$ & $\begin{array}{l}14 \\
13\end{array}$ & $\begin{array}{l}18 \\
11\end{array}$ & ' \\
\hline $\begin{array}{l}" 1 \\
" 1 \\
" 1\end{array}$ & $\begin{array}{c}\mathrm{Co}^{60}-\gamma(1.3 \mathrm{Mev}) \\
" 1 \\
"\end{array}$ & $\begin{array}{l}60 \\
16 \\
81 \\
81\end{array}$ & $\left.\begin{array}{c}15 \\
4 \\
4 \\
2\end{array}\right)$ & $\left.\begin{array}{r}19 \\
17 \\
4 \\
2\end{array}\right\}$ & $\begin{array}{c}" \text { " } \\
\text { " } \\
\text { Paper chromatography }\end{array}$ \\
\hline$\left[\begin{array}{c}\left.\left(\mathrm{CH}_{3}\right)_{3} \mathrm{NCH}_{2} \mathrm{CH}_{3}\right]^{+} \mathrm{Cl}^{-} \\
" \\
"\end{array}\right.$ & $\begin{array}{c}\text { 2-4-Mvelectrons } \\
" ~ \\
" \\
"\end{array}$ & $\begin{array}{l}123 \\
172 \\
208 \\
166\end{array}$ & $\begin{array}{c}3 \\
24^{\mathrm{e}} \\
3 \\
2\end{array}$ & $\begin{array}{r}2.3 \\
13^{2} \\
1.3 \\
1.1\end{array}$ & $\begin{array}{c}\text { Reineckate } \\
" 1 \\
" \\
"\end{array}$ \\
\hline $\begin{array}{l}\text { "" } \\
\text { ", } \\
\text { ", } \\
\text { " }\end{array}$ & $\begin{array}{c}\mathrm{Co}^{60}-\gamma(1.3 \mathrm{Mev}) \\
" 1 \\
" 1 \\
" ~ \\
" ~\end{array}$ & $\begin{array}{l}30 \\
28 \\
29 \\
52 \\
29 \\
50 \\
50\end{array}$ & $\left.\begin{array}{c}11^{e} \\
1 \\
0 \\
0 \\
0 \\
3 \\
2\end{array}\right\}$ & $\begin{array}{c}34^{\mathrm{e}} \\
\left.\begin{array}{l}3.3 \\
\mathrm{v} . \mathrm{low} \\
" 1 \\
" 1 \\
5.6 \\
3.7\end{array}\right\}\end{array}$ & $\begin{array}{l}" \text { " } \\
\text { Paper chromatography } \\
\text { Reineckate } \\
" " \\
\text { " } \\
\text { Paper chromatography }\end{array}$ \\
\hline
\end{tabular}

e This value is almost certainly high and is probably due to an error in carrying out the reineckate 


\section{Discussion}

Choline chloride is by far the most unstable of the seven members of this series studied and is, by any criterion other than polymerization, the most radiation-sensitive organic compound known at the present time. Its very high $G$ value and lack of diversity of products clearly indicate the presence of a chain mechanism of decomposition. Since about $25-30$ ev are required to ionize an organic molecule, a $G$ value in the range of about 3 to 4 indicates that, assuming ionization rather than excitation is playing the dominant role, approximately every molecule that is ionized is subsequently irreversibly converted to some other chemical species. In the case of the self-decomposed $C^{14}$-labeled choline chloride, with a $G$ value of something like 1000 , approximately 300 choline ions are decomposed by the energy required to ionize a single molecule. Therefore, the decomposition of the labeled choline chloride may be proceeding through a free-radical chain mechanism which starts with a single +2 choline ion and continues through about 300 ions before the chain reaction is terminated. What part, if any, excited molecules play in the decomposition mechanism is unknown. The only facts known at present about the postulated chain reaction are (a) the energy of activation is high enough so that the chain does not proceed at liquid nitrogen temperatures, and (b) the presence of radiation-produced iodine, in the case of the choline iodide, also breaks the chain in accordance with iodine's known behavior of reacting rapidly with free radicals. 12 One way in which the chain reaction may be taking place is the following:

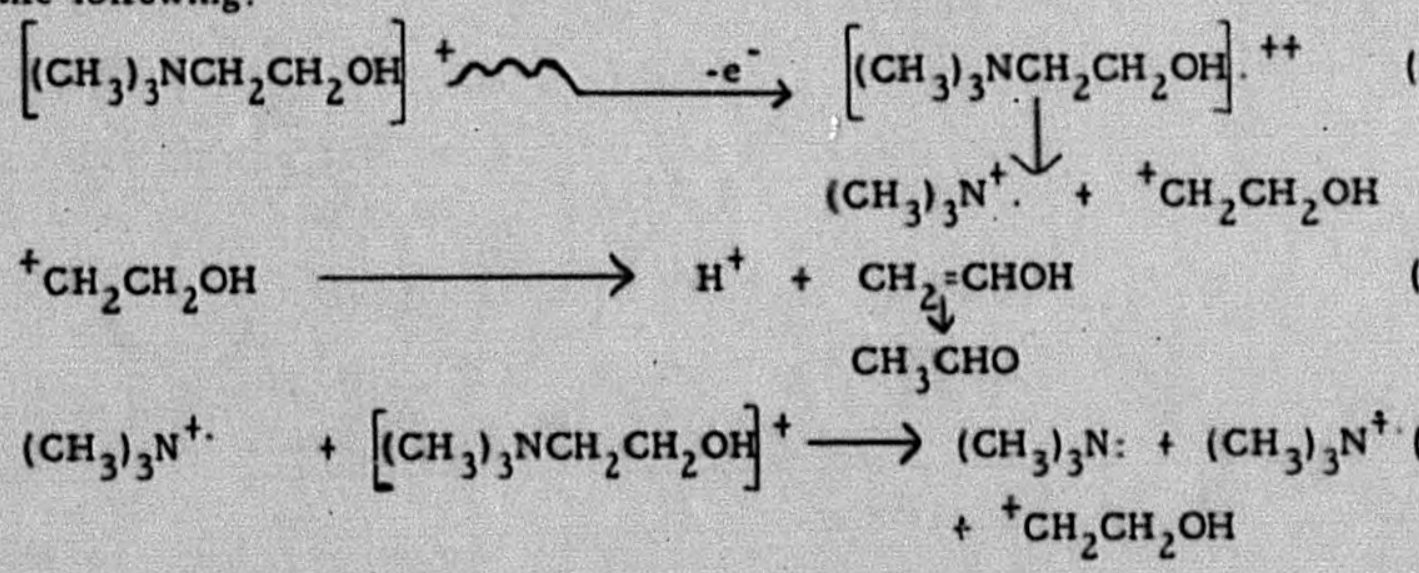

Reactions (2) and (3) might then be repeated until the trimethylamine radical-ion participated in some reaction other than (3), thus breaking the chain. However, since the crystal structure of choline chloride has not been determined, it is not known whether the spatial arrangement of atoms in a choline chloride crystal is such as to favor the operation of this mechanism. It is probable, however, that the crystal structures of the choline analogs, when they are accurately known, will do much to explain the great difference in radiation sensitivity between choline chloride and the other choline analogs.

T2 J. L. Magee, Ann. Rev. Nuclear Sci. 3, 187 (1953). 
The explanation of the great difference in the $G$ values of the $\mathrm{C}^{14}$-beta- and the 2-4-Mv electron-decomposed choline chloride may lie in either (a) the ggeater density of lonization in the primary events resalting from the low-energy $\mathrm{C}^{14}$ betas, or (b) the far higher flux of electrons in the case of the high-energy particles; the higher-energy irradiations took place during a few minutes, the lowv-energy ones during weeks or months.

By analogy with the work of Ingold's group ${ }^{13}$ on the thermal decomposition of quaternary ammonium bases (Hofmann elimination reaction), it might be expected that trimethyl-2-chloroethyl ammonium chloride, with an even stronger electron-attracting group on the $\beta$-carbon atom, might be even more unstable than choline chloride. However, the former compound is much more stable towards radiation decomposition than choline chloride. Since a chain mechanism apparently ts present in the case of choline chloride, but not in any of the analogs (with the possible exception of betaine hydrochloride), the radiation-decomposition reaction is quite different from the thermal decompositions and no analogies can be drawn. It is possible that, were it not for the operation of the chain reaction, the trimethyl-2-chloroethyl ammonium chloride might actually be more radiation-unstable than choline chloride.

\section{Acknowledgment}

The authors wish to acknowledge the very helpful adivice and suggestions of Professor Melvin Calvin and Dr. Bert M. Tolbert. We are also indebted to Mr. Duane Moshier and Dr. R. Stephan White for advice and assistance in the high-energy electron irradiations.

13 C. K. Ingold, "Structure and Mechanism in Organic Chernistry," Cornell University Press, 1953, pp. 427-434. 